\title{
Dark Heritage
}

\section{Thomas, Suzanne Elizabeth}

Springer

2019-08-22

Thomas , S E , Herva , V-P , Seitsonen , O \& Koskinen-Koivisto, E 2019 , Dark Heritage . in C Smith (ed.) , Encyclopedia of Global Archaeology . Living Edition edn , Springer , Cham . https://doi.org/10.1007/9

http://hdl.handle.net/10138/318535

https://doi.org/10.1007/978-3-319-51726-1_3197-1

acceptedVersion

Downloaded from Helda, University of Helsinki institutional repository.

This is an electronic reprint of the original article.

This reprint may differ from the original in pagination and typographic detail.

Please cite the original version. 
Thomas S., Herva VP., Seitsonen O., Koskinen-Koivisto E. (2019) Dark Heritage. In: Smith C. (eds)

Encyclopedia of Global Archaeology. Springer, Cham

\section{Introduction}

The concept of "dark heritage" has gained traction in recent years in archaeology and in cultural heritage studies more broadly. Its origins lie in the somewhat more specific field of "dark tourism" studies. Both dark heritage and dark tourism are rather vague terms in their current usage, but they generally revolve around places of death, suffering, and disaster, whether battlefields, concentration camps, or notorious sites of disaster such as Chernobyl. Indeed, dark tourism studies have tended to assume that death, and an attraction to death, is a central trope of both dark heritage and dark tourism. However, dark heritage is better seen in broader terms, that is, as an attempt to expand the scope of heritage studies.

There are several terms that are closely connected to "dark heritage," including "difficult heritage," "contested heritage," "dissonant heritage," and "negative heritage." These terms have started to appear frequently in the heritage discourse fairly recently, and, like dark heritage, they lack established and generally agreed on definitions. There are both overlaps and different emphases between these terms, but "difficult heritage," for instance, can be understood as broader in scope than dark heritage. Essentially, however, all these terms - including dark heritage - represent an attempt to expand the scope of heritage studies and diversify heritage meanings, recognizing that heritage is multivocal, controversial, and frequently problematic. There is an increasing awareness that heritage comes also in diverse "negative" forms, such as environmental pollution, social inequality, and poverty, inherited from the past and having myriad impacts in the present.

\section{Definition}

"Dark heritage" research explores the concept of cultural heritage as a potentially "dark" force. In other words, dark heritage researchers are interested in how and why people choose to engage with aspects of cultural heritage that are related to times of conflict, death, and suffering. These aspects may have different meanings for different groups or communities depending, for instance, upon their role in the conflict, temporal distance from the events, and hierarchies of power.

Researchers have noted that while similar terms exist, dark heritage seems somehow to encapsulate also the complexity of the social impact, multifaceted aspects, and politically charged nature of this kind of heritage. While dark tourism studies initially tended to emphasize death as a key theme, it seems evident that reducing the meaning of dark heritage to the fascination with death and the macabre is too simplistic. Indeed, one of the potential benefits of the concept of dark heritage is that it enables pursuing heritage values - or how and why the past in the present matters - beyond the traditional frameworks of heritage thinking. Understanding the reasons for the attraction of dark heritage is nonetheless a common theme and a central challenge to dark tourism studies and dark heritage studies. For instance, Eerika KoskinenKoivisto has used dark heritage as an umbrella term, to refer to "several related concepts that are connected with dark, macabre, difficult and even painful elements of cultural heritage" (Koskinen-Koivisto 2016: 24). Traditionally, heritage studies have tended to prioritize or concentrate on monumental and aesthetically pleasing remains of the past, whereas dark heritage grasps the significance and meanings of "heritage that hurts" (Sather-Wagstaff 2011), negative and unpleasant things inherited from the past, having an impact on the present in one form or another. Thus conceived, the idea of dark heritage represents an attempt to establish a more balanced understanding of how and in what forms the past is present in the present, in recognizing the diversity of impacts that both recent and more distant past has on contemporary issues. When editing a themed journal issue on "dark heritage," Julie Carr and Mike Corbishley reflected on their process on selecting the term "dark heritage" for the collection: 
"Originally, our working title was 'difficult heritage', but, as discussions with contributors progressed, it became clear that this term was not nuanced enough. Because these articles relate to events which might shock, unsettle, shame, or enrage, we have chosen to use the term dark heritage. . ." (Carr and Corbishley 2015: 1).

Some forms of dark heritage, such as concentration camps (Fig. 1), are officially and formally identified as heritage and incorporated in heritage protection schemes, as reflected in their listing as national heritage or UNESCO World Heritage sites, whereas difficult heritage in the form of, for instance, pollution is usually not discussed in heritage terms. However, an awareness of how such issues - or "unwanted" remains from the past - are linked to heritage matters is currently increasing. Dark heritage, then, can also refer to certain ignored types of sites and materialities inherited from the past, but it may also be conceived as an aspect (rather than merely a type) of'heritage overlooked within the established or "authorized" heritage discourse. Thus, for instance, the suffering associated with (early) industrial work could be treated as dark heritage, while industrial architecture, for instance, may be listed as heritage on more traditional heritagevalues grounds. In other words, dark heritage embraces the past in the present in less sanitized and unpolished terms than traditional heritage discourses. As dark heritage is troublesome or shameful, it often becomes silenced and thus excluded in narratives and representations of local and/or national history (see Thomas and Koskinen-Koivisto 2016). Commonly, dark heritage relates to the cultural legacy of major conflict events such as the Second World War (WW2), as in the case of the project Lapland's Dark Heritage which has studied, in 2014-2018, the Nazi German presence in Finnish Lapland, first as Finland's cobelligerent in 1941-1944 and then as an enemy in 1944-1945 (e.g., Herva et al. 2016; Koskinen-Koivisto and Thomas 2016) (Fig. 2). In other cases, the term has been used in the context of a longer period of violence and political unrest, including state responses to such situations, as in the case of Laura McAtackney's (2014) research on the controversial Long Kesh/Maze prison in Northern Ireland.

\section{Historical Background}

The closely related idea of "dark tourism" appears to have originated with Malcolm Foley and J. John Lennon (1996: 195) as a means of recognizing the process of visiting, primarily as tourists, heritage sites connected with atrocity "for remembrance, education or entertainment."

Influenced by these and other scholars, Philip Stone (2006) developed a "spectrum" of dark tourism, in which individual attractions may Dark Heritage, exhibit different degrees of "darkness" (Fig. 3).

Fig. 1 Rails leading to Auschwitz, probably the most well-known Second World War Nazi concentration and extermination camp, Poland. (Photograph: Bundesarchiv, B 285 Bild-04413/Stanislaw Mucha/CC-BY-SA 3.0)

Factors affecting the extent to which a tourist attraction is dark may include such variables as authenticity and the extent to which the attraction has been commoditized for touristic consumption. The darkest sites are those that have the least tourism infrastructure and the worst atrocities associated with them; thus death camps are arguably the darkest of these sites (Stone 2006: 157).

Dimitrovski et al. (2017: 696) have noted the relationships between notions of dark heritage and dark tourism, critiquing the overuse of the latter, as visitor motivations are often more complex and nuanced, noting that many touristic sites demarcated as "dark" are also heritage sites:

“...dark heritage sites could be perceived in a broader local, regional, or national historical context. The labelling of such places as dark tourism sites depends on their level of darkness. The difference between an ordinary heritage site and a dark heritage site is determined by the shade of darkness, with the darkest sites such as those of genocide and death camps on one side of the spectrum, to those such as battlefields - viewed as profound heritage 
experiences without any special interest in death itself - on the other side. Commemorative events are perceived as part of national and personal intangible heritage, but simultaneously, they have dark attributes which gives them the annotation of dark heritage events."

There are clearly many overlaps between difficult, contested, and dark heritage, although - inspired by its sister term "dark tourism" - dark heritage as it is currently understood always has an element of physical conflict, destruction, or other atrocity, which may include but also go beyond other, less physically violent or specific event-related, controversies. Therefore, "dark" heritage is always "contested" and "difficult," but "difficult" and "contested" heritage is not always necessarily "dark." In a recent review of the past couple of decades of dark tourism scholarship, Duncan Light suggested some conflation between dark tourism and related terms such as "dark heritage tourism" and "dark heritage" (Light 2017).

Dark Heritage, Fig. 2 The Norvajärvi Mausoleum in Rovaniemi, where the remains of the German Second World War soldiers recovered in Finnish Lapland are interred. (Photograph: Oula Seitsonen 2016)

However, some scholars arguably lean toward the term "dark heritage" specifically rather than "dark tourism" in recognition that "dark" heritage sites have more than just a touristic value. That is to say, that the heritage aspects of the dark heritage under scrutiny may or may not also have touristic aspects and values and vice versa.

Dark heritage practices may also include, for example, collecting material connected to wartime (e.g., Thomas et al. 2016: 336). It is also recognized that the "dark" aspects of cultural heritage may be just one facet of the overall "value" of the heritage; other aspects making the cultural heritage meaningful to people might include the geographical or temporal proximity between those who engage with it and the historical events to which it relates (e.g., Koskinen-Koivisto and Thomas 2016: 121). The presence of WW2, for example, within the living memory of many people, or at least of relatives and friends that they remember, as well as the continued legacy of the war within popular culture, may go to explain the huge interest that many have in that period (Fig. 4).

\section{Key Issues/Current Debates}

Debate around this still-new term has been in some cases related to discussions concerning the coining of the related term dark tourism (discussed above) where some have critiqued this process of the term's development. There have been suggestions that it has become a "research brand," cautioning that assumptions must not be made about the purpose of visitors to such attractions nor the significance of the perceived "darkness" in motivating the visit (Yankholmes and McKercher 2015: 235).

Dark Heritage, Fig. 3 Philip Stone's (2006) dark tourism spectrum: perceived product features of dark tourism within a "darkest-lightest" framework of supply. (Drawn after Stone 2006: 151)

Critiques of the prevalence of the term "dark" in this context and that of "dark tourism" could be that connotations could be read into its use for denoting negative and "evil" heritage as an indication drawing ethnic or racial parallels. Goldenberg (2009), for example, has highlighted the uses of black and white as metaphors for good and evil as having their roots in racist thinking. However, even research that has looked especially at Black understandings and experiences of, for example, slave heritage as dark tourism, have not problematized the terminology in this way (e.g., Mowatt and Chancellor 2011). Nonetheless it is an important issue to be mindful of as the term gains more usage within scholarship.

Like all heritage, dark heritage is polysemous and multivocal. It is important to note and reflect on different perspectives to dark heritage that heritage professionals and other interest groups, including researchers themselves, may have. Researchers need to ask who labels the heritage dark, who are those who want to 
engage with it, and to whom this heritage might be unwanted and difficult. For instance, exit surveys of people with different (national) backgrounds showed very different reactions to a temporary exhibition in Rovaniemi in 2015-2016 of the peaceful coexistence of Finns and Germans in northern Finland during WW2. Locals tended to feel that their past and wartime experiences were finally recognized after decades of overlooking and marginalization, whereas visitors from many other countries felt that the rather neutral portrayal of German soldiers as ordinary human beings, as opposed to Nazi monsters, was disgraceful and offensive (Herva et al. 2016). Similarly, it is clear that within heritage discourses generally there is an element of power concerning how different heritage is framed, sometimes regarding the extent to which different aspects of the heritage are either emphasized or silenced: "The knowledge that dark heritage sites can have a variety of meanings for the various publics that wish to consume them can result in contested and politically loaded sites being overly controlled and interpreted through state interventions" (McAtackney 2014: 229).

Dark Heritage, Fig. 4 Hiroshima Peace Memorial, registered as a UNESCO world heritage site in 1996, against the city's modern buildings, Japan. (Photograph: CC BY-SA 2.0, https://commons. wikimedia.org/w/index. php?curid=245138)

War, and WW2 in particular, is a recurrent theme in dark heritage and dark tourism studies. An interest in and appropriation of Nazis (e.g., in the form of collecting Nazi paraphernalia) might, at the outset, seem to be a form of dark heritage engagement, but such a priori assumptions and generalizations may also be problematic and misleading, as it is not necessarily fascination with Nazi ideology and atrocities that motivates collecting or related practices. Rather, the appeal to Nazi heritage may stem from an interest in local history and heritage, as studies in Finland, for instance, have indicated (Herva et al. 2016; Thomas et al. 2016). Although such seemingly "innocent" engagements with difficult pasts can be understood in terms of dark heritage just as well, it is nonetheless important not to avoid making too many assumptions about why different people are interested in dark heritage. The perception of this apparent "darkness" in connection to dark heritage does indeed vary for the consumer of that heritage, affected by personal or family connection, locational closeness to the event to which the heritage relates, political leanings, and many other variables. Therefore one of the challenges that researchers have sometimes faced has come from individuals interacting with the heritage, who may question whether the heritage should be labeled as "dark" at all (see Koskinen-Koivisto and Thomas 2016).

Besides death and suffering in the most immediate sense, dark heritage can be related to a host of broader themes, including broad-ranging existentialist matters, as well as more specific matters such as failures or dark sides of (super)modernity (Fig. 5). While some dark heritage practices are rather distinctively associated with particular subcultures or specialized hobbies - sometimes illicit, clandestine, or suspicious in nature (Thomas et al. 2016) - other forms of dark heritage are popular and thoroughly commercialized. These include, for instance, places like "torture museums" and practices like ghost walks and ghost hunting, which are nevertheless within the dark heritage field, even if in the lighter end of the spectrum. Issues of and curiosity with decay and ruination, for instance, may be seen to resonate, to at least some degree, both with existential matters in a broad sense and with anxieties of modernity more specifically (see, e.g., Stone and Sharpley 2008).

These heritage engagements would appear to suggest that destruction in its different forms is a central issue of dark heritage and an element of how and why dark heritage appeals to people. Dark heritage speaks of dimensions of human life and experience, which are integral to being human, yet largely ignored within the traditional - and arguably dominant - idea of what heritage is about. Moreover, since many dark heritage sites are not listed and protected as heritage, they afford forms of engagement that would be unacceptable at official heritage sites, and they provide opportunities for "unmediated" encounters with the past in the present differently from museum and curated heritage sites. For example, increasingly 
globalized economies and the changing character of industrial production in the Western world has had myriad negative impacts, which can be explored within a framework of dark heritage.

More concretely, modernity and its failures have left behind (industrial) ruin landscapes, wastelands, substantial dumps of waste, and other such negative heritage. This heritage (although not necessarily identified as such within authorized heritage discourses) attracts all kinds of attention and practices, including the hobby known as urban exploration and the anesthetization of destruction, decline, and decay (see Olsen and Pétursdóttir 2014).

Deliberate destruction and desecration of cultural heritage are forms in which dark heritage comes into being. This befalls most often in the conflict contexts, for instance, when one community tries to eradicate the memories and rights of another group, but also as collateral damage, like in many places during WW2, such as at Dresden, Monte Cassino, and Norwegian and Finnish Lapland (Fig. 6). Some recent examples include the destroying of Stari Most Bridge in Mostar during the Yugoslavian Civil War (e.g., Wollentz 2017), the blasting of the Bamiyan Buddhas by the Al-Qaida in Afghanistan (e.g., Francioni and Lenzerini 2006), and the widespread devastation caused by the so-called Islamic State of Iraq and the Levant (ISIL/ISIS), for example, at the UNESCO World Heritage site of Palmyra, which received wide social media coverage (e.g., Harmanşah 2015). The deliberate destruction and its effects on, for instance, the communal memory, identity, and reconciliation, have so far received limited attention from a heritage perspective but have vast potential for wider research (e.g., Giblin 2014; Seitsonen and Koskinen-Koivisto 2018).

\section{International Perspectives}

Dark heritage study is a distinctively international field, and the themes central to it have been pursued around the world. This of course is expected in the view that dark heritage largely revolves around issues that are characteristic to the modern world, whether industrialized warfare (including the legacy of nuclear weapons testing and other environmentally catastrophic and ethically dubious practices), industrialization/deindustrialization (including industrial disaster), large-scale pollution of the environment, or consequences of climate change and their impact upon cultural and intangible heritages.

Dark Heritage, Fig. 5 Remains of a Soviet weather station and military base abandoned in 1992 on the New Siberian Islands in the High Arctic Russia. (Photograph: Oula Seitsonen 2004)

\section{Future Directions}

The concept of dark heritage is not necessarily new, even if its name arrived quite recently, but it is a notion which is still in flux. As perceptions of heritage - within academic discourse and also within communities themselves - fluctuate over time, so will ideas of what constitutes "darkness" within those viewpoints and definitions. It is sadly the case that "new" dark heritage will continue to be generated as conflicts and other disasters continue to break out and later resolve, and unfortunately atrocities continue to be committed by states, splinter groups, and others. Deliberate destruction of heritage due to its heritage status is to be included within this.

Horror and fantasy as literary and popular culture genres were long regarded as a subculture but have become mainstream in Western culture over the 2000s, with, for instance, television shows about vampires, zombies, and ghosts being aired prime time, as exemplified by the series like Most Haunted and Walking Dead. These themes closely resonate with the themes central to dark heritage, and this popularization of the dark may be expected to emerge as a subject of an increasing interest also in dark heritage studies. This development coincides with the recent interest in ghosts, haunting, and the uncanny in various disciplines across humanities and social sciences. 
This is perhaps particularly clearly reflected in the field of human geography where the concept of haunting has been productively deployed for many years toward a better understanding of, for instance, the significance and experience of modern ruins as part of modern cultural landscapes (e.g., DeSilvey and Edensor 2012). Dark heritage, in other words, is likely to become a more mainstream field of research with links to various disciplines.

Dark Heritage, Fig. 6 Monastery of Monte Cassino, the birthplace of the Benedictine Order, in ruins after Allied bombing in 1944, Italy. (Photograph: Bundesarchiv, Bild 146-2005-0004/Wittke/CC-BY-SA 3.0)

Dark heritage also represents a logical expansion of the questions we ask of cultural heritage studies in general. University courses focusing on dark heritage as a theme for learning are emerging across the world, suggesting that future researchers will continue the interest in this area.

Dark heritage can also be a useful source for history teaching in the form of school visits. Meanwhile, cultural heritage is also brushing alongside future studies, with concerns about such issues as toxic and nuclear waste (e.g., Harrison et al. 2016), suggesting development also of related areas of inquiry. Issues of pollution and the Anthropocene would also seem to be emerging as increasingly important research themes. While these topics may appear to be somewhat different from the "classical" dark heritage issues, where dark heritage was understood primarily as negative and hurting heritage, they do actually represent a logical continuum to and development of this subfield of heritage studies. Subsequently, dark heritage studies will provide different angles on, for instance, the questions of nature-culture relation or the human relationship with the world (e.g., Olsen and Pétursdóttir 2014). In this respect, then, the field of dark heritage studies reflects the changing and broadening field of heritage studies in general, with previously marginalized issues becoming mainstream.

\section{References}

Carr, J., and M. Corbishley. 2015. Editorial. Conservation and Management of Archaeological Sites 17 (1): 13. https://doi.org/10.1179/1350503315Z.00000000097.

Desilvey, C., and T. Edensor. 2012. Reckoning with ruins. Progress in Human Geography 37 (4): 465-485. https://doi.org/10.1177/0309132512462271.

Dimitrovski, D., V. Senić, D. Marić, and V. Marinković. 2017. Commemorative events at destination memorials-a dark (heritage) tourism context. International Journal of Heritage Studies 23 (8): 695-708.

https://doi.org/10.1080/13527258.2017.1317645.

Foley, M., and J.J. Lennon. 1996. Editorial: Heart of darkness. International Journal of Heritage Studies 2 (4): 195-197. https://doi.org/10.1080/13527259608722174.

Francioni, F., and F. Lenzerini. 2006. The obligation to prevent and avoid destruction of cultural heritage: From Bamiyan to Iraq. In Art and cultural heritage: Law, policy and practice, ed. B.T. Hoffman, 28-40. Cambridge, UK: Cambridge University Press.

Giblin, J.D. 2014. Post-conflict heritage: Symbolic healing and cultural renewal. International Journal of Heritage Studies 20 (5): 500-518. https://doi.org/10.1080/13527258.2013.772912.

Goldenberg, D. 2009. Racism, color symbolism, and color prejudice. In The origins of racism in the west, ed. M. Eliav-Feldon, B. Isaac, and J. Ziegler, 88-108. Cambridge, UK: Cambridge University Press.

Harmanşah, O. 2015. ISIS, heritage, and the spectacles of destruction in the global media. Near Eastern Archaeology 78 (3): 170-177. 
Harrison, R., N. Bartolini, C. Desilvey, C. Holtorf, A. Lyons, S. Macdonald, S. May, J. Morgan, and S. Penrose. 2016. Heritage futures. Archaeology International 19: 68-72. https://doi.org/10.5334/ai.1912.

Herva, V.-P., E. Koskinen-Koivisto, O. Seitsonen, and S. Thomas. 2016. 'I have better stuff at home':

Treasure hunting and private collecting of World War II artefacts in Finnish Lapland. World Archaeology 48 (2): 267-281. https://doi.org/10.1080/00438243.2016.1184586.

Koskinen-Koivisto, E. 2016. Reminder of the dark heritage of humankind - experiences of Finnish cemetery tourists of visiting the Norvajärvi German cemetery. Thanatos 5 (1): 23-42.

https://thanatosjournal.files.wordpress.com/2016/06/koskinen-koivisto_dark_heritage.pdf.

Koskinen-Koivisto, E., and S. Thomas. 2016. Lapland's dark heritage: Responses to the legacy of World War II. In Heritage in action: Making the past in the present, ed. H. Silverman, E. Waterton, and S. Watson, 121133. New York: Springer. https://doi.org/10.1007/978-3-319-42870-3_9.

Light, D. 2017. Progress in dark tourism and thanatourism research: An uneasy relationship with heritage tourism. Tourism Management 61: 275-301. https://doi.org/10.1016/j.tourman.2017.01.011.

McAtackney, L. 2014. An archaeology of the troubles: The dark heritage of long Kesh/maze prison. Oxford: Oxford University Press.

Mowatt, R.A., and C.H. Chancellor. 2011. Visiting death and life: Dark tourism and slave castles. Annals of Tourism Research 38 (4): 1410-1434.

Olsen, B., and P. Pétursdóttir. 2014. Ruin memories: Materiality, aesthetics and the archaeology of the recent past. Oxon: Routledge.

Sather-Wagstaff, J. 2011. Heritage that hurts: Tourists in the memoryscapes of September 11. Walnut Creek: Left Coast Press.

Seitsonen, O., and E. Koskinen-Koivisto. 2018. 'Where the F. . . is Vuotso?': Heritage of Second World War forced movement and destruction in a Sámi Reindeer Herding community in Finnish Lapland. International Journal of Heritage Studies 24 (4):421-441. https://doi.org/10.1080/20518196.2016.1252129.

Stone, P. 2006. A dark tourism spectrum: Towards a typology of death and macabre related tourist sites, attractions and exhibitions. Tourism: An Interdisciplinary International Journal 54 (2): 145-160.

Stone, P., and R. Sharpley. 2008. Consuming dark tourism: A thanatological perspective. Annals of Tourism Research 35 (2): 574-595.

Thomas, S., and E. Koskinen-Koivisto. 2016. 'Ghosts in the background' and the 'Price of the war': Representations of the Lapland war in Finnish museums. Nordisk Museologi 2016 (2): 60-77.

Thomas, S., O. Seitsonen, and V.-P. Herva. 2016. Nazi memorabilia, dark heritage and treasure hunting as "alternative" tourism: Understanding the fascination with the material remains of World War II in Northern Finland. Journal of Field Archaeology 41 (3): 331-343. https://doi.org/10.1080/00934690.2016.1168769.

Wollentz, G. 2017. Making a home in Mostar: Heritage and the temporalities of belonging. International Journal of Heritage Studies 23 (10): 928-945. https://doi.org/10.1080/13527258.2017.1347891.

Yankholmes, A., and B. McKercher. 2015. Rethinking slavery heritage tourism. Journal of Heritage Tourism 10 (3): 233-247. https://doi.org/10.1080/1743873X.2014.988159. 